\title{
Experience in Correcting the Distribution of Iron and Aluminum Impurities in the Technical Grade Beryllium
}

\section{S. S. Martynenko ${ }^{1}$ and V. I. Petrov ${ }^{2}$}

${ }^{1}$ Department of Instrument and Installation Design, National Research Nuclear University MEPhl (Moscow Engineering Physics Institute), Kashirskoe shosse 31, Moscow, 115409, Russia ${ }^{2}$ General Chemistry Department, National Research Nuclear University MEPhl (Moscow Engineering Physics Institute), Kashirskoe shosse 31, Moscow, 115409, Russia

\section{Abstract}

The example of beryllium of technical purity shows the possibility of introducing changes in the distribution of impurities between different phases during the operational period. The feeding and prolongation of the active action of one of the secondary phases, which favorably affects the properties of the material, is carried

Corresponding Author: Petrov Valeriy Ivanovich vipetrov@mephi.ru

Received: 21 December 2017 Accepted: 15 April 2018

Published: 6 May 2018

Publishing services provided by Knowledge $\mathrm{E}$

(c) S. S. Martynenko and V. I. Petrov. This article is distributed under the terms of the

commons Attribution License, which permits unrestricted use and redistribution provided that the original author and source are credited.

Selection and Peer-review under the responsibility of the MIE-2017 Conference Committee.

\section{G OPEN ACCESS}

out. The data on the redistribution of iron and aluminum impurities were obtained by Mössbauer spectroscopy. Spectra were received after homogenization, at the intermediate stages and after completion of isothermal annealing at $600^{\circ} \mathrm{C}$ with the total endurance of more than $1100 \mathrm{~h}$. The intermediate secondary phase $\mathrm{AlFeBe}_{4}$ prevails during more long-lived time term than with the ordinary content of aluminum. Methods for correcting the distribution of impurities are discussed.

Keywords: distribution of impurities, correcting, Mössbauer spectroscopy, beryllium of technical purity

\section{INTRODUCTION}

The properties of metals and alloys often depend on the structural-phase state of the impurities. Changing this state can affect the service life of the entire material.

Beryllium is used in a number of nuclear reactors as a reflector and moderator and is a key material in a thermonuclear project, it is used in instrument engineering and other types of equipment. A positive effect of the $\mathrm{AlFeBe}_{4}$ type triple-phase precipitates on mechanical properties is noted [1-3]. On the other hand, with the course of operation, for example, with the accumulation of a large dose of neutron irradiation, gradual degradation of the material is observed [4-7]. It is required from metal to maintain acceptable properties for long time, and here, in our opinion, the data on redistribution of impurities would be useful. 
In the present paper, one-time feeding of the triple phase with aluminum was carried out to evaluate the controllability of the distribution and structural-phase changes, and Mössbauer studies of beryllium were carried out. The Mössbauer spectra were taken after homogenization and prolonged annealing.

\section{MATERIALS AND METHODS}

Mössbauer spectra were obtained. Measurements of the effect on transmission were carried out on a spectrometer MC1101E with a resonant detector of the RSDU type (Rostov), a 57Co radiation source in chromium (Rivertz) was used. Samples were in the form of plates with a thickness of $1.5-2 \mathrm{~mm}$. The gamma radiation source, detector and sample were placed in a thermostat in which a constant temperature of $25.0^{\circ} \mathrm{C}$ was maintained. The known Mossbauer parameters of the solid solution of iron in beryllium and the secondary phases of FeBe11 and AlFeBe 4 were used for identification [8-11].

For the detailed interpretation of the spectra and the identification of various states, the most reliable data were selected by comparing different calculation methods. It is possible to resolve complex transmission spectra with small and close lines, study redistribution of iron between different phases, analyze dissolution and precipitation processes.

The model beryllium of the technical purity containing a small amount of aluminum (0.03 wt. \%) had been chosen as initial. The material also contained of the iron (0.11 wt. \%) enriched with the isotope ${ }^{57} \mathrm{Fe}$. The content of the other metal impurities did not exceed $0.05 \mathrm{wt} . \%$ in total. The alloy had been homogenized at $1000^{\circ} \mathrm{C}$ whereupon the spectrum contained only the doublet of the solid solution.

Earlier, the precipitation of various phases in beryllium of technical purity during heat treatment was observed $[1,3,11-15]$. In the usual working state, after preparatory technological annealing, technical beryllium usually has a Mössbauer spectrum consisting of doublet lines of solid solution and one or two secondary phases. The spectrum of a typical sample is shown in Fig. 1.

It has been shown that with time at a given temperature the triple phase gradually weakens [11-13].

As a method of redistribution of impurities in favor of the triple phase, in principle, periodic or constant saturation of the surface of beryllium components with aluminum can be used, followed by equalization of its concentration by heat treatment. 


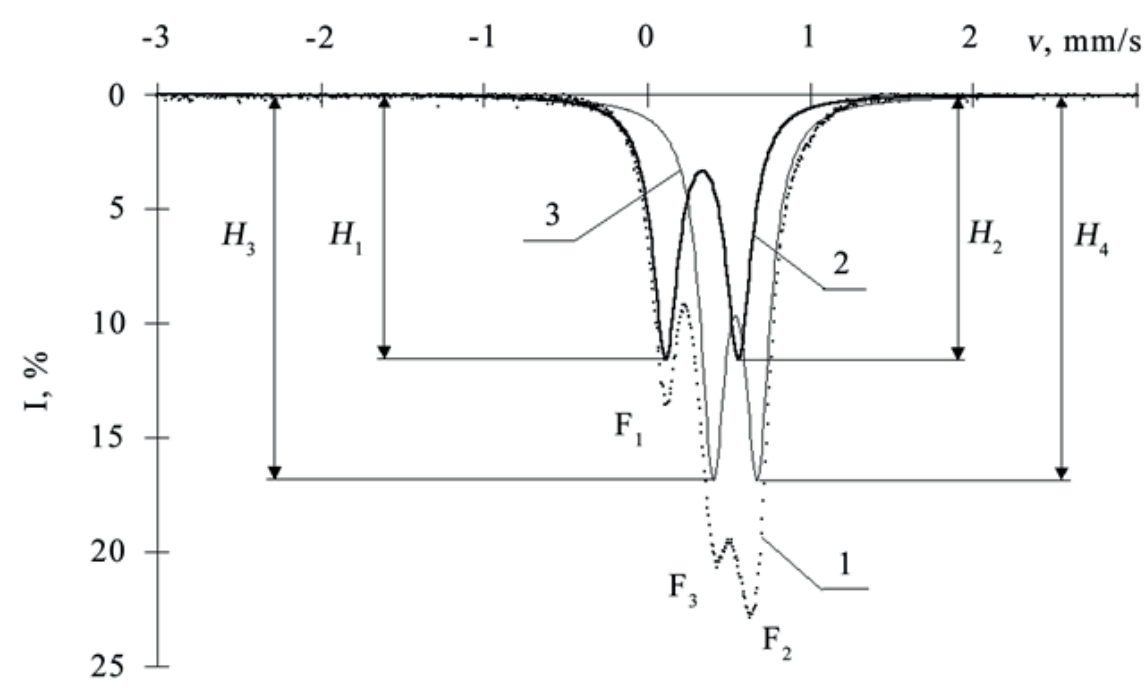

Figure 1: The spectrum of the ordinary technical beryllium: 1 - experimental spectrum; 2 - doublet of the solid solution; 3 - doublet of the secondary phase; $H_{1}, H_{2}$ - line amplitudes of the solid solution doublet; $H_{3}$, $H_{4}$ - line amplitudes of the secondary phase doublet; $F_{1}, F_{2}, F_{3}$-intensities of the experimental spectrum peaks.

Choosing a method of saturation of the surface, we will consider two processes: 1) introduction by means of beam technologies and 2) penetration with direct contact of metals.

Saturation of metal surfaces by the first method is methodically debugged $[16,17]$. Using this method, it was possible to determine the region of existence of the ternary phase in the beryllium angle of the Be-Al-Fe system state diagram [14, 15]. Since in our case there are a number of impurities in the metal, first of all iron, to evaluate the efficiency of the method we will use the results of the introduction of aluminum into beryllium in competition with iron described in work [18].

A double film of Al-Fe (at first iron, then aluminum) or Fe-Al (in reverse order) was applied on the beryllium. Further, applying a beam of $\mathrm{Ar}^{+}$ions with a wide power range, an interval of doses was $(1-10) \cdot 10^{18} \mathrm{ion} / \mathrm{cm}^{2}$, the metal atoms were implanted by the ionic mixing method (fig. 2. The drawing is borrowed from work [18], but contains some schematic additions). Note, that in the both cases atoms of iron penetrated deeper than aluminum atoms. The penetration of aluminum depends on the presence of iron atoms in the matrix and film.

Unfortunately, the low-temperature implantation process and its dependence on iron impurities do not yet ensure equalization of aluminum concentration throughout the material; the method requires refinement. 


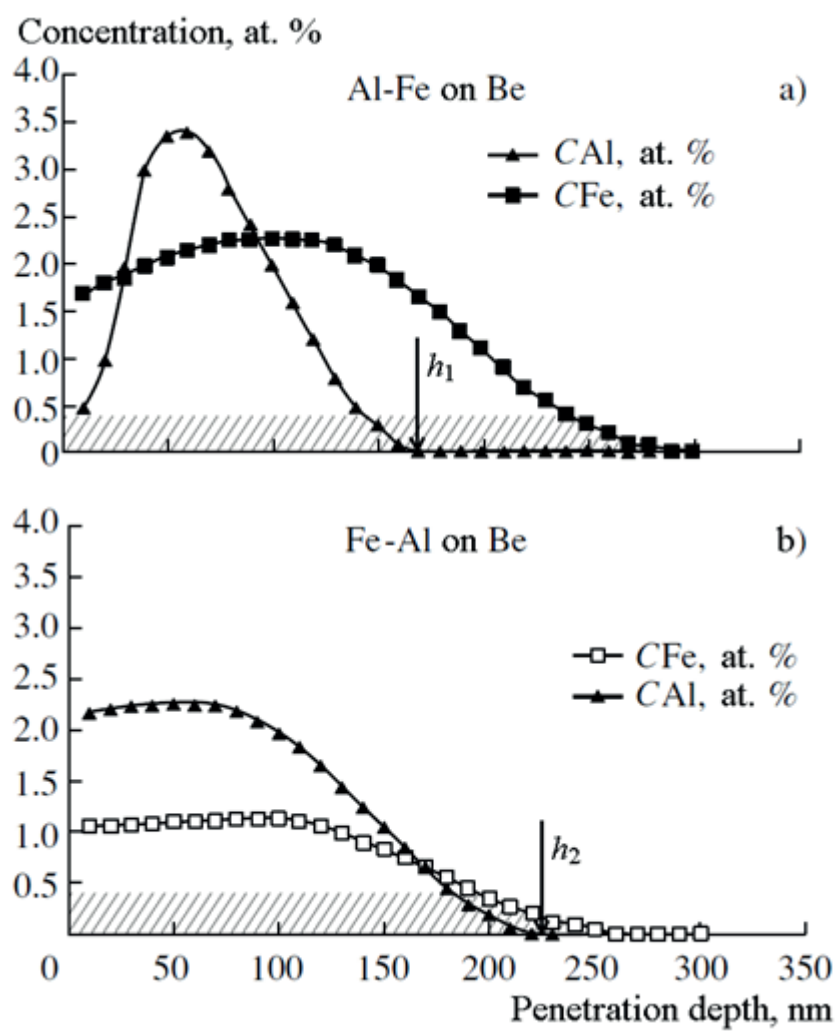

Figure 2: Distribution of the atoms of aluminum and iron in beryllium implanted by the ionic mixing method from films of Al-Fe (a) and Fe-Al (b) on beryllium at the irradiation by the beam of ions of $\mathrm{Ar}^{+}$with the wide energy distribution up to a dose of $1 \cdot 10^{18}$ ion $/ \mathrm{cm}^{2}[18] ; h_{1}$ and $h_{2}$ - the depth of the aluminum atoms penetration for " $a$ " and "b" options respectively; the shaded area schematically corresponds to the content of iron in the solid solution.

More preferable is high-temperature saturation with direct contact of the beryllium component with aluminum. This method is also interesting in connection the wellknown proposal to enclose beryllium blocks in an aluminum shell in one of the research reactors [7].

In the present work, the aluminum content in the test material was brought from the minimum to the upper level, characteristic for technical purity. This was done as follows. The samples were maintained in contact with pure aluminum briefly at $700{ }^{\circ} \mathrm{C}$ (up to its fusion) and then at $645^{\circ} \mathrm{C}$, with the subsequent fast cooling (the solubility of aluminum at $645^{\circ} \mathrm{C}$ is the highest). In this way, one-time make-up is carried out with aluminum.

Homogenization was then carried out at $1000^{\circ} \mathrm{C}$. Aluminum diffuses faster than iron and other impurities [3], therefore, at an elevated temperature, the leveling of its concentration proceeds more quickly.

Then, a long (more than $1100 \mathrm{~h}$ ) isothermal annealing was carried out at $600{ }^{\circ} \mathrm{C}$. The analysis is a simplified model of practical operation. The temperature is chosen to accelerate diffusion processes. The normal operating temperature of the material 
is not higher than $400{ }^{\circ} \mathrm{C}$, and the diffusion processes proceed slowly, however they accumulate in long campaigns, such as the working period of a nuclear reactor.

The spectra were obtained after homogenization, at intermediate stages and after the completion of isothermal annealing.

\section{RESULTS AND DISCUSSION}

As a result of aging in contact with aluminum and subsequent homogenization, the average aluminum content in the samples increased to $0.15 \mathrm{wt}$. \%. It was mainly located along the grain boundaries. The Mossbauer spectrum again showed only the presence of a solid solution of beryllium-iron, the weak solubility of aluminum on the spectrum was not affected. No other iron-containing phases were detected except for the solid solution.

Long-term isothermal annealing has made major changes. Fig. 3 shows the change in the content of different phases.

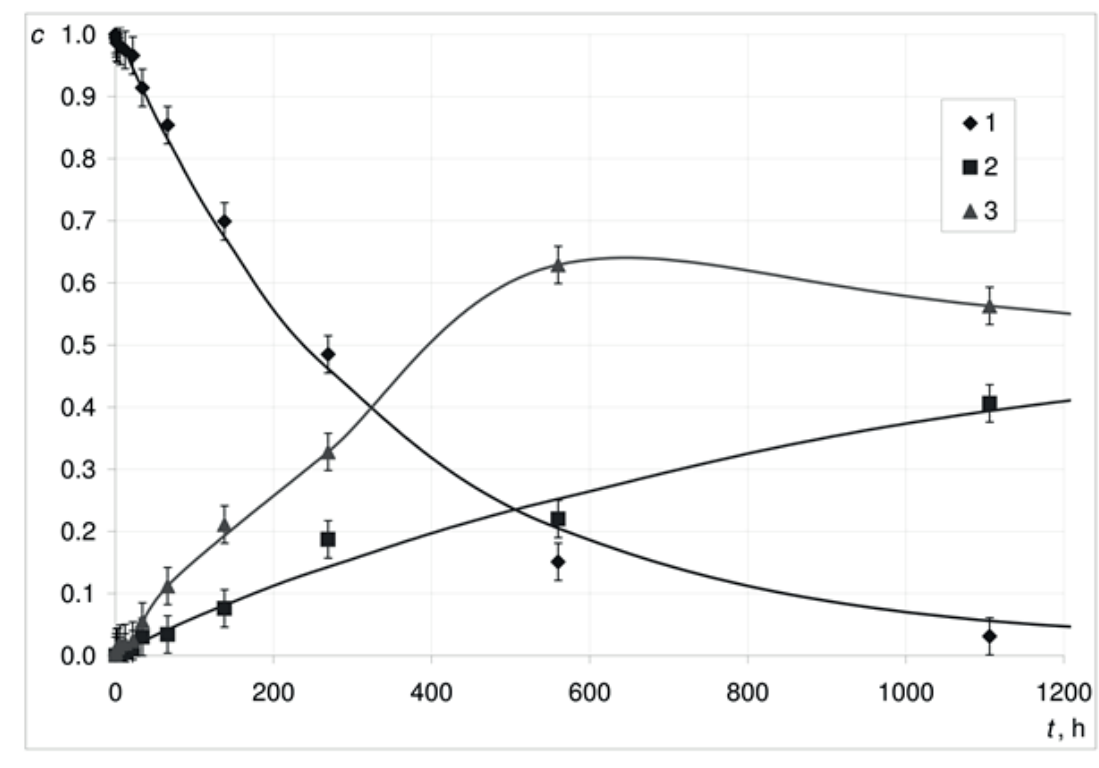

Figure 3: The iron content in the various phases of the beryllium at the isothermal annealing: 1-the solid solution; 2 - the phase of the $\mathrm{FeBe}_{11}$ type; 3 - $\mathrm{AlFeBe}_{4}$ phase.

After $350 \mathrm{~h}$ after the start of annealing, the proportion of iron in the AlFeBe ${ }_{4}$ phase exceeded its share in the solid solution, and after $300 \mathrm{~h}$ the excess was more than 3 times. In both cases, the proportion of iron in the triple phase was twice that in the double phase. And then a relatively high content of the triple phase was observed during a time interval exceeding the usual one corresponding to a lower aluminum content. In contrast to the new data obtained, earlier, with a lower content $[12,13]$, 
the behavior of the alloys was characterized by the gradual decomposition of the solid solution, the predominance of the binary phase over the triple phase and the establishment of a certain phase relationship, and with long exposures, this ratio remained almost unchanged.

It follows from the comparison of the data that the contact of the sample with aluminum provided a one-time supply of the triple phase. More substantial recharge can be expected from a longer or recurring contact. Apparently, the marked excess of the triple phase is a characteristic feature for a given impurity composition, taking to account the increased aluminum content.

The AlFeBe ${ }_{4}$ phase with an isomer shift of $0.57 \pm 0.01 \mathrm{~mm} / \mathrm{s}$ and a quadrupole splitting of $0.28 \pm 0.01 \mathrm{~mm} / \mathrm{s}$ is satisfactorily identified from the literature data, the second iron-containing phase with an isomer shift of $0.54 \pm 0.01 \mathrm{~mm} / \mathrm{s}$ and with a quadrupole splitting of $0.14 \pm 0.01 \mathrm{~mm} / \mathrm{s}$, taking to account the literature data, we are approximately classed as $(\mathrm{Fe}, \mathrm{M}) \mathrm{Be}_{x}$ : in comparison with $\mathrm{FeBe}_{11}$ it has a somewhat higher isomeric shift, which may indicate a partial substitution of iron on other metal impurities $(M)$ and the complexity of the lattice.

The possibility of redistribution during long-term annealing helps to uncover the mechanism of complex processes during operation and to approach their management. With a decrease in the proportion of the triple phase, its effect on the physical and mechanical properties of the material is gradually weakened. Apparently, there is some critical portion of this phase that should be supported. To maintain this fraction, a certain composition of impurities should be selected. Perhaps the contact of beryllium blocks with an aluminum shell will play a positive role. Then, during annealing, and, possibly, during irradiation, constant replenishment of AlFeBe ${ }_{4}$ segregation is possible. On the other hand, a number of other methods, for example, multilayer ion implantation, can also be proposed to regulate the penetration of aluminum and the constant recharge of grain-boundary segregations, after further development of an appropriate ion mixing and leveling-out regime.

\section{CONCLUSIONS}

1. According to Mossbauer spectroscopy data, during long-term annealing of technical beryllium with elevated aluminum content, the secondary phase of $\mathrm{AlFeBe}_{4}$ predominates over a longer period of time than with the usual aluminum content.

2. In the case of contact of beryllium blocks with an aluminum shell during annealing and irradiation, the grain-boundary segregation AlFeBe ${ }_{4}$ can be continuously 
replenished, with a corresponding extension of its positive effect on the operational properties of the material.

The example of beryllium of technical purity shows the possibility of targeted changes in the distribution of impurities between different phases during the operational period.

\section{ACKNOWLEDGMENT}

This work was supported by the MEPhl Academic Excellence Project (agreement with the Ministry of Education and Science of the Russian Federation of August 27, 2013, project no. 2.a03.21.0005).

\section{References}

[1] The Beryllium science and technology, eds D. Webster et al, New York, Plenum Press, 1979.

[2] V. M. Azhazha, A. V. Babun, K. V. Kovtun, F. P. Sanin, and A. F. Sanin, "Berilii - konstruktsiinii mterial aero kos- michnoi tekhniki (Beryllium is the structural material of air-space technique)". Dnepropetrovsk: ART-PRES, 2005 (In Ukrainian).

[3] I. I. Papirov, Struktura I svoistva splavov berilliya, Spravochnik (Structure and properties of beryllium alloys. Handbook), Moscow, Energoizdat, 1981 (in Russian).

[4] R. Chaouadi, A. Leenaerts, J. L. Puzzolante, and M. Scibetta, "Radiation effect on the mechanical properties of irra- diated beryllium", Proceedings of the 4th International Workshop on Beryllium Technology for Fusion, Karls ruhe, Sept. 1999, FZKA-6462, Karlsruhe, Fusion Technology, Apr, pp. 233-246, 2000.

[5] A. O. Posevin, and V. P. Chakin, Berillii pod oblucheniem: obzor (Beryllium under irradiation: review), Dimitrov grad, NIIAR, 2007 (in Russian).

[6] V. Chakin, A. Moeslang, M. Svyatkin, A. Posevin, P. Vladimirov, and R. Latypov, "Beryllium application for fis sion and fusion". Proceedings of the International Symposium on Materials Testing Reactors, JAEA Oarai R@D Center, Japan, July 16-17, 2008. Oarai: R@D Center, pp.107-116, 2008.

[7] R. N. Latypov, Teploprovodnost berilliya posle oblucheniya do vysokoi povrezhdayuschei dozy (Heat conductivity of the beryllium after a high doze), Thesis, Moscow, VNIINM, 2012, 29 p. (in Russian).

[8] C. Janot, and H. Gibert, "Etude par effet Mössbauer de la precipitation du fer dans le beryllium", Mater. Sci. Eng., vol. 10, no. 1, pp. 23-31, 1972. 
[9] C. Janot, and P. Delcroix,."Mössbauer studies of electronic properties of iron impurities in hexagonal closed-packed metals", Phil. Mag., vol. 30, pp. 651-655, 1974.

[10] O. C. Kistner, and B. Mozer, "Origin of the Mössbauer adsorption spectra of ironimpurity atoms in beryllium", Bull. Amer. Phys. Soc. vol.7, no. 7, pp. 505-508, 1962.

[11] G. N. Belozersky, V. A. Grigoriev, V. A. Ivanov, V. G. Semenov, A. Yu. Sokolov, and A. A. Aleksandrov, "Protsessy pereraspredeleniya zheleza $v$ berillii technicheskoi chistoty (Processes of iron redistribution in be rylliums of technical purity)", Pisma v Zhurnal Tekhnicheskoi Fiziki (Technical Physics Letters), vol. 13, no. 9, pp. 531-534, 1987 (In Russian).

[12] V. P. Filippov, V. I. Petrov, S. S. Martynenko, and V. A. Salomasov, "Second particles precipitations in Be-Fe al loys", Hyperfine Interactions, vol. 237, no. 112, pp. 1-7, 2016.

[13] V. P. Filippov, V. P. Gladkov, S. S. Martynenko, and V. I., "Solid solution decomposition and growth of precipi tates in Be-Fe alloys from Mössbauer investigation", Hyperfine Interactions, vol. 226, no. 1-3, pp. 365-373, 2014.

[14] S. M. Myers, and J. E. Smuguresky, "Phase equilibria in Fe-Al-Be system using highenergy ion beams", Metal. Trans., vol. 7A, pp. 795-802, 1976.

[15] S. M. Myers, and J. E. Smuguresky, "Phase equilibria in Fe-Al-Be system using highenergy ion beams", Metal. Trans., vol. 9A, pp. 1789-1794, 1978.

[16] Surface modification and alloing by laser, ion, and electron beams, J. M. Poat, G. Foti, and D. C. Jacobson, eds, New York, Plenum Press, 1983.

[17] B. A. Kalin, N. V. Volkov, I. V. Oleinikov "Ion mixing in multilayer films and doping in near-surface layers of polycrystalline under irradiation by ion beams with awide energy spectrum", Bulletin of the Russian Academy of Sciences: Physics, vol. 76, no. 6, pp. 690-695, 2012.

[18] N. V. Volkov, and B. A. Kalin, "Osobennosti raspyleniya mnogosloinykh Al, Ti, Fe, Mo plyonok na berillii pri obluchenii polienergeticheskim puchkom ionov $\mathrm{He}^{+} \mathrm{i} \mathrm{Ar}^{+}$so srednei energiei 10 keV", Poverkhnost. Rent genovskie, sinkhrotronnie i neitronnie issledovaniya (Journal of Surface Investigation: X-ray, Synchrotron and Neutron Techniques), no. 5, pp. 38-42, 2003 (In Russian). 